\title{
CLAVE ÁRABE PARA EL REPARTIMENT DE VALENCIA*
}

\author{
Carmen Barceló \\ Universitat de València
}

\begin{abstract}
Resumen: El trabajo muestra cómo el Repartiment de Valencia oculta bajo letras latinas una serie de nombres de persona, topónimos y otros datos en árabe que, actualmente, están ocultos por efecto de ediciones poco exigentes. Los resultados de una nueva lectura, debidamente trabajados y cotejados con los de otras fuentes, permiten reconocer a un gran número de personajes de la élite social musulmana de Valencia en la primera mitad del siglo XIII y sus propiedades. También es posible ubicar barrios, calles, edificios y otros elementos urbanos, lo que permite ampliar la visión que ahora se tiene de la ciudad islámica.
\end{abstract}

Palabras clave: Al-Andalus, Valencia, siglo XIII, prosopografía, toponimia urbana, Repartiment.

\section{Arabic clue to the Repartiment of Valencia}

Abstract: This article shows that the book of the Repartiment of Valencia hides under its Latin script personal names, place names and other data in Arabic which have been until now hidden due to inaccurate editions. With the good readings, studied and collated with data from other sources, it is possible to recognize a large number of characters of the Valencian Muslim elite in the first half of the 13th century and their properties. It is also possible to locate neighborhoods, streets, buildings and other urban elements that allow us to enlarge the vision we now have of the Islamic City.

Key words: Al-Andalus, Valencia (Spain), 13th. c., Prosopography, urban toponymy, Repartiment.

Es bien sabido que las conquistas de la ciudad y reino de Valencia por Jaime I comportaron la expulsión de los antiguos ciudadanos musulmanes y una repoblación que preparó personalmente el rey. El reparto de tierras se llevó a cabo de forma lenta, con muchas donaciones que se recogieron en pergaminos, cartas de población y otro tipo de documentos, como los tres libros que guardan el Repartiment, conservados en el archivo de la Corona de Aragón (ACA), conocidos de cualquier persona interesada por los inicios y constitución del antiguo reino.

Próspero de Bofarull (1856) publicó la primera edición de estos libros en la colección de documentos inéditos del ACA (CODOIN). A pesar de ser una edición incompleta y poco crítica, con ella se inició el análisis de esta fuente y los estudiosos obtuvieron muy buenos resultados sobre todo de tipo histórico y toponímico. Merecen un breve recuerdo los trabajos pioneros de Chabás (1844-1912), que realizó varios índices muy útiles, y los estudios de Ribera (1858-1934) quien, además de tratar sobre algunos aspectos de la población musulmana de Valencia usando el Repartiment (Ribera, 1928), en el prólogo de su

Data de recepció: 21 de març de 2016 / Data d'acceptació: 17 de maig de 2016.

* El presente texto es reelaboración del que, con el título "El Llibre del Repartiment de València: un palimpsest àrab?", leí en el Seminario de Estudios Medievales, organizado por el Departament d'Història Medieval de la Universitat de València y dirigido por Antoni Furió (13.10.2014). 
edición fotocópica se ocupó de las dificultades codicológicas y paleográficas que ofrece el documento (Ribera, 1939); y aún resultó útil, antes de la llegada de otras ediciones, para estudiar la ciudad islámica de Valencia (Barceló, 1975).

En el contexto de las negociaciones políticas para definir las señas de identidad del País Valencià salieron en 1979 dos nuevas ediciones. En Zaragoza, en tres volúmenes, se publicó la realizada por Cabanes y Ferrer. La otra, con un tomo que reproducía los tres libros, apareció en Valencia; junto a la edición, hecha por varios colaboradores bajo la dirección de Ferrando, hay traducción catalana ${ }^{1}$. Los dos trabajos editoriales llevan índices, pero con errores en la identificación de onomásticos y topónimos, como pasa también en los índices de Bofarull (Chabás, 1883-1889).

Presento aquí un avance del resultado de contrastar en las tres ediciones los materiales árabes. Recojo aquello que desde el punto de vista onomástico e histórico parece más seguro y poco dudoso.

\section{EL MANUSCRISTO ÁRABE OCULTO}

El Repartiment tiene muchos datos que se pueden abordar desde el punto de vista de los estudios árabes, como los inmuebles urbanos y los bienes raíces de los musulmanes valencianos, sus onomásticos, la topografía de la capital y la toponimia del reino. El manuscrito del Repartiment en su versión conservada romanceado-latina oculta un original árabe, tal vez oral, por lo que podríamos calificarlo metafóricamente de "palimpsesto".

Recuerdo que palimpsesto, adaptación casi exacta del griego clásico $\pi \alpha \lambda$ í $\mu \psi \eta \tau$ 七o (que quiere decir "que se borra repetidamente"), se dice del pergamino o papiro cuyo escrito se limpia para volver a escribir sobre él. Fue práctica común en la Edad Media raspar los pergaminos ya escritos para volver a usarlos y a pesar de eso, siglos después, los expertos pueden descubrir qué había escrito en ellos mirándolos con nuevas técnicas. Las investigaciones más recientes señalan (McKitterick, 2007) que la mayor parte de los palimpsestos citados por los grandes eruditos del pasado son textos cristianos que se reemplazan por otros porque la escritura antigua ya no es inteligible.

En los libros del Repartiment la parte confusa no es la que se expresa en catalán, aragonés o latín, sino la que informa sobre los anteriores pobladores cuyos nombres y oficios se escribían y decían en lengua árabe. De modo que el manuscritro del Repartiment ha conservado muchas pistas sobre la época árabe anterior, como si fuese un palimpsesto, manteniendo bajo la grafía latina, que es un inadecuado modo de escribir el árabe, los nombres de las tierras y de los anteriores habitantes de la ciudad; por eso se ha convertido en un texto ininteligible o difícil de leer sin la llave árabe.

Así pues, si los libros del Repartiment de Valencia son un viejo manuscrito árabe, ¿cómo podemos trabajar para leer lo borrado por las letras latinas? Se debería trabajar con una metodología asentada en el atento examen de los manuscritos y renovada, aplicando las nuevas técnicas en el tratamiento de datos e imagen y auxiliada de paleografía, filología, crítica textual, historia de las instituciones, de la cultura y de las mentalidades. En resumen, con un equipo formado por expertos en estas disciplinas.

1 Transcripción: J. Camarena, L. Cerveró, J. Corell, J. Villalmanzo, A. Ferrando. Índices: J. Corell, J. Villalmanzo, J. Climent, A. Ferrando. Introducción y traducción al catalán: A. Ferrando. 


\subsection{Los métodos}

En el presente estudio conviene prestar atención a la serie de problemas de edición que generó la acción de los escribas medievales pues, siglos después, requieren un especial tratamiento para hallarles solución. Hemos de tener presente que esos escribanos no hablaban árabe y tenían unos usos de escritura que no eran los más adecuados para representar los diferentes sonidos de la lengua del Alcorán.

Escribir los sonidos de una lengua con los grafemas de otra es un grave problema que exige consenso, incluso en la era de la informática, porque se trata de adaptaciones subjetivas. Por lo tanto, hemos de aceptar que no es posible establecer para el pasado leyes infalibles que regulen las transcripciones o transliteraciones, entre otras razones porque en ningún caso son iguales los sistemas y porque entonces no existían tampoco sistemas ortográficos normativos o normativizados de las lenguas de los escribanos.

De manera que podemos esperar que copista y escribano adaptaran las voces árabes al alfabeto latino que usaban para redactar y escribir en aragonés o catalán; y no solo eso, porque también añadían la declinación de caso cuando redactaban en latín, como ocurre en el Repartiment. Quizá un escriba conociera el árabe dialectal pero transcribía a letras latinas lo que oía o creía oír. Para podernos mover por el marasmo de transliteraciones de voces árabes a los otros idiomas es necesario conocer tanto la lengua árabe clásica y dialectal como el estadio medieval de las lenguas receptoras, así como los usos gráficos para representarlas según el buen saber y entender de quien escribía.

Además, los copistas interpretan las grafías de los documentos sin conocer el árabe. Por eso cometen bastantes errores. Son buena prueba las enmiendas (tachones, rayados, añadidos) presentes en los tres libros, uno de los principales problemas para la correcta lectura y/o interpretación del texto; aparte de los relativos a la codicología que, como han señalado sus editores, les afectan de forma especial.

El reflejo del árabe en grafía latina plantea otra casuística: interpretar cada vocablo considerándolo elemento de un sistema codificado que al pasar por una fase acústica se ha cifrado en otro sistema, de sonido y grafía diferente. La interpretación del amanuense cristiano podría causar hechos favorables porque, gracias a su ignorancia de los sonidos, la morfología y la tradición gráfica del árabe, tenía plena libertad para reproducir lo que oía y tal como lo oía. Pero eso no sucede siempre así. Es sabido que la percepción de sonidos de otra lengua lleva a interpretar, en primer lugar según el sistema de sonidos del oyente. En el caso de los notarios de la Corona de Aragón su sistema era el romance y los sonidos inexistentes en románico se adaptaron, fijándose por escrito tan solo una parte de las características articulatorias árabes: modo, punto, sonoridad...

En el momento de plasmar las voces con grafía latina el escriba sigue la influencia de los hábitos ortográficos de su propia lengua y la presión de sus morfemas y sufijos, a los que tiende a asimilar los sonidos árabes -incluso aunque los perciba diferentes- en un intento (inconsciente tal vez) de evitar grafías anómalas en romance o en latín (aunque no sea su lengua natural). Por ello, las variadas o vacilantes grafías que a menudo se pueden recoger para cada fonema árabe no muestran rasgos del dialecto árabe sino la dificultad del escriba para identificar y reproducir, con letras latinas y corrección, sonidos que no diferenciaba en romance o que desconocía; dificultades analizadas al estudiar la onomástica y la toponímia árabe valenciana (Labarta, 1989; Barceló, 1983; Barceló, 2010). 
Es cierto que el sentido común nos hace considerar normales estos obstáculos porque hablamos de lenguas diferentes. Pero desde el punto de vista de lo que trato ahora, el manuscrito árabe ha quedado dañado por la acción del copista, ya que el Repartiment de Valencia no es original sino copia de otros documentos. Son prueba de ello las variantes gráficas de un único nombre propio que recoge el muestrario de los patronímicos árabes valencianos (Barceló, 2000).

\subsection{Errores gráficos}

Junto a los errores de los copistas medievales hay otros debidos a los editores modernos pues, a veces por su insuficiencia de técnica paleográfica y otras por su inopia del árabe, interpretan ciertos caracteres latinos de manera inexacta. Y aunque no haría falta decirlo, hay que añadir a todo ello las fatales erratas de imprenta. Se borran así del documento signos que bien editados y anotados ayudarían a interpretar mejor este texto. Las dudas paleográficas, agravadas en quien desconoce el árabe, provocan las erratas más comunes de los editores. Veamos ejemplos de diferencias gráficas en las tres ediciones ${ }^{2}$.

Es frecuente la confusión $<\mathrm{n}\rangle,\langle\mathrm{u}\rangle \mathrm{y}<\mathrm{v}>$. Un caso entre otros: Aben 'Abdu rabbi-h es dueño de un huerto en Roteros ${ }^{3}$. Según la práctica de los copistas del Repartiment se esperaría un Aben Abdorap pero se ha editado Abnaudorap (B 246.1), Abnaudorap (F 1148), Abnandorap (CF 1:1383). Sea por copia o por edición otros ejemplos afectan también a $<\mathrm{h}>$, además de $\langle\mathrm{u}\rangle,\langle\mathrm{v}\rangle,\langle\mathrm{n}\rangle$. Se donaron casas a Joan Periç de Pavia que fueron de:

-Abrahim Abivaleva in vico de Avensalma et de Aciça (B 156.3).

-Abrahim Abivaleva, in vico de Avensalmo, et de Açiça (F 70).

-Abrahim Abin Aleva, in vico de Aven Salma et de Açiça (CF 1:70).

El asiento de esta donación lleva un signo al margen; poco después se copia el mismo (aquí sin esa marca) y el nombre se ha interpretado de manera diferente porque lleva $<\mathrm{h}>$ :

-Abrahim Abinhalela Alquiteni et de Açiça que sunt in vico de Avensalmo (B 297.8).

- Abrahim/ Abinhalela \Alquiteni/ et de Açiça que sunt in vico de Avensalmo (F 1586).

-Abrahim Abinhalelar et de Açiça Alquiteni, que sunt in vico de Avensalmo (CF 1:1021). Es probable que en esta segunda donación el Llibre recoja el onomástico y la situación correcta; y en efecto, el parcelario de la ciudad cita a "Açiça" ( 'Až̄za), esposa (zawja) del dueño de la casa cedida a Periç de Pavia: "domos Zaug Abenhalela" (Abrāhīm aben Halīla al-Kittān̄̄) (B 608.12; F 3685; CF 3:2313). Con esto se confirma que hay un error en el nombre del varón en la primera donación y sospecho que su posesión estaba en el barrio de Aben Šalbūn, en la partida que después habitaron los hombres de Teruel.

A veces confundir $\langle\mathrm{c}\rangle,\langle\mathrm{t}\rangle,\langle\mathrm{r}\rangle$ puede causar duplicidad si editor o escribano omite o desarrolla mal una abreviatura. Se ve en la transcripción de Benimàmet (Bañ̄ Ma 'bid) (Barceló, 1983, s.v.), desde las más aproximadas "Benimabet” (B 278.4; F 1402), "Benimahabet" (B 204.5; F 666), a "Benimabar" (F 1062), "Benimahor" (B 190.1, 205.7; F 483, 832; CF 1:488, 1:675, 1:1291), "Beniamhabar" (CF 1:1354), "Benimahabar" (B 242.5; F 1117, 1118; CF 1:677, 1:1353), “Benimanhor” (B 204.3, 205.12, 248.1; F 681, 685; CF 1:692, 1:696, 1:1395).

\footnotetext{
${ }^{2}$ Se respetan los símbolos usados por los editores. B 1.2 identifica Bofarull, página.asiento; CF 1:2, Cabanes y Ferrer volumen: asiento; F 1, Ferrando, n. ${ }^{\circ}$ de asiento.

${ }^{3}$ Utilizo la transcripción del árabe del Institut d'Estudis Catalans.
} 
Alararif, citado en una donación al obispo de Segorbe (B 175.10; F 311; CF 1:313), es evidente error por "Motarif". La casa de cierto "Abdalla Mutarif" ( Abd Allāh Muțarrif) fue dada a Gil Garcés (B 529.8; F 3276; CF 3:372). En este asiento el nombre se copia bien pero en otro se ve la confusión <t>, <r>; así, Fátima (Fāṭima), mujer de "Amet Abeniopar" (Ahmmad aben Jubayr), poseía el "ortum Abdela Morarif” (B 160.1; F 120; CF 1:120). Sin dejar a Fátima, la vemos citada en una donación a Bernat de Calvera ${ }^{4}$ : filia Dabimfilel et uxor de Amet Abenjopar (B 172.2); fila de Avinfilel et uxor de Hamet Abenjopar (F 254); fila d'Avinfilel et uxor de Hamet Abeniopar (CF 1:255).

En alguna edición <-im-> se ha leído <-iu-> o <-in->. Así, "Yçmel Alxauri" (B 239.6), "Yçmel Alxinri" (F 1090) e "Yçmel Alximi” (CF 1:1236), "Azmel Alxiuri” (F 1007; "Alximi” CF 1:1326) , es decir un hombre de Algímia (Ismā'̄ll al-Jāmi"). De pasada, diré que su huerto lindaba con el de "Halhaix" ( $a l-H \bar{a} j j)$ que -aunque varón- aparece en dos de las ediciones identificado como "filia de Anaxe" (B 239.6; F 1090).

El nombre del propietario de un huerto aparece editado con transcripciones erráticas: orto de Abdohaolich Min Abrahim Abençahol Alquiteni (B 248.5); orto de Abdohaolich Min Abrahim Abençahol Alquiteni (F 1164); orto de Abdohaelich Min Abrahim Abençahol Alquiteni (CF 1:1399). Creo que "Min" oculta el árabe Aben "hijo". El escriba no copió bien ni el nombre ni la filiación del dueño del huerto ( 'Abd al-Malik aben Abrāhīm aben Sah[a]l al-Kittān̄̄).

Otro caso parecido se ve en la donación de "domos de" Abrahim de Paterna Alfachar Abinmenimabat juxta domum de Aly Alpegui (B 306.2); Abrahim de Paterna Alfachar Binmenimabat iuxta domum Aly Alpegui (F 1668); Abrahim de Paterna, Alfachar Abinmenimabat, iuxta domum de Aly Alpegui (CF 1:1103). ¿Qué significa "Paterna Alfachar Binmenimabat"? Aquí, aunque la confusión podría deberse al oído del escriba, estamos ante un problema de copista o de editores. Sospecho que el dueño de la casa fue Abrāhīm al-Bațarnī, es decir Abrāhīm, natural de Paterna (Bațārna), de oficio "alfarero de Benimàmet" (al-faxxār min Ban̄̄ Ma 'bad) como dice otro asiento que recoge una donación a Sanç de Estada de "domos et hereditatem" "de Habraim Alfachar in Benimahabet" (B 204.5; Habrahim F 666; et est in Benimahaber CF 1:677).

Solo a un escriba poco avisado se puede deber que el nombre bíblico de varón Moisés traslade un Nuzha, nombre de la hermana del gobernante Zayyān aben Mardanīš que gozaba del título "Alhorra" (al-hurra "la libre"): "Musa" (B 294.6; F 1557 pero WNuja/ F 411; Muza CF 1:992, Muça Alharra CF 1:413). Estaba casada con un hombre que a tenor de las ediciones tanto pudo llamarse "Abovaqui" (B 294.6; F 1557; CF 1:992) como "Abocequi" (F 411; CF 1:413). He de señalar que en los mismos asientos el nombre del gobernante musulmán se halla anotado una vez "Zahen", con $<\mathrm{h}>$ (CF 1:413), y otra "Zayen", con <y> (F 411), o mudando <z> en <ç> "Çayen" (B 294.6; CF 1:992; F 1557). ¿Es un problema del escribano o de comprensión paleográfica?

En ocasiones bajo el texto latino puede leerse el árabe -escrito quizá siguiendo al oído al informante. Así se descubre la preposición dialectal matā', similar a nuestra "de", en una donación hecha "in villa de Boatela" que registra "carrarias quarum una dicitur": 2197).

${ }^{4}$ En el parcelario se cita Hamet Abenchopar en las casas dadas a este Bernat (F 3661; CF 3:2196,

${ }^{5}$ A partir de aquí para evitar molestas duplicaciones, indico la variante en la referencia bibliográfica. 
-Rabat Macalcama, secunda Rahat Abingaçi, tercia Rabat Alborgi et dividit cum alfundicho Mataben Eacob quod est in carraria Dalbenhaux (B 237.3).

-Rabat Matalcama; secunda, rabat Abingaçi; tercia, rabat Alborgi; et dividit cum alfundicho Mataben Eacob, quod est in carraria d'Albenhaux (CF 1:1312).

-Rabat Matalcama; secunda, Rahat Abingaçi, tercia, Rabat Alborgi, et dividit cum alfundicho Mataben (Jacob) Eacob, quod est in carraria de Albenhanx (F 1077). Además el término árabe rahbat (plaza), tiene en un solo asiento -según ediciones- una o dos grafías latinas "rahat" - "rabat"; y el deformado "Albenhanx" es "la puerta de la Culebra" (bāb al-Hanaš) que sitúa la alhóndiga de Aben Ya'qūb (al-fundiq matā' Aben Ya qū̄b). El asiento muestra un error usual de las ediciones: no segmentar correctamente los términos.

Hay muchas transcripciones en las que se detecta el olvido por parte del copista de un signo de abreviatura. Sirva de ejemplo que cuando se hizo la primera donación de un huerto en la Almunia de los Pinos (munyat al-șanābīr) el escribano copió bien "Muinet Açanabir" (B 168.7; F 223; Açanibir CF 1:224); al repetir más adelante el topónimo en otro asiento el amanuense ignoró la abreviatura y anotó "Muinhet Acebir" (F 475; Açebir CF 1:480).

Hasta aquí hemos visto algunos problemas relacionados con los criterios de edición del registro. He hablado de ello sin referirme a otras cuestiones relativas a la codicología, como el orden de los cuadernos, los símbolos añadidos en los márgenes de los asientos o los tachones, rayas y añadidos que se encuentran en ellos.

\section{LOS MUSULMANES DEL REPARTIMENT}

Me referiré ahora a temas de carácter interno del Repartiment. En fechas no muy lejanas el Llibre se ha usado para tratar de fijar el origen geográfico de los repobladores de la ciudad y reino de Valencia; todo ello en la búsqueda de antepasados de procedencia mayoritaria catalana o aragonesa, trasladando una ideología nacionalista burguesa totalmente ajena a la época medieval, queriendo hacer que la balanza se incline hacia uno de los dos orígenes según tendencias políticas -hoy afortunadamente relegadas- olvidando los más elementales principios de la sociolingüística.

La población musulmana, por contra, no ha despertado tanta curiosidad. Para conocer la trayectoria de cristianos y judíos se acude a registros reales, textos eclesiásticos, donaciones en pergaminos, cartas de población, notales, etc.; por lo que respecta a los musulmanes, se busca el concurso de textos literarios, diccionarios biográficos, documentos y crónicas árabes. La mayor parte de los cristianos y musulmanes que cita la fuente que analizo pertenecía a las corporaciones artesanales o al campesinado; no así los judíos, que normalmente no cultivaban la tierra. Algunos judíos eran médicos o menescales de la Casa real, por eso se les llama alfaquí (al-hakīm), lo que ha dado pie a erróneas confusiones sinonímicas con el término técnico islámico (Chabás, 1892, 249) que sin embargo son fáciles de resolver, ya que los judíos recibieron donaciones y heredades.

En el Repartiment los onomásticos de varón musulmán son mucho más abundantes que los de mujer, algo totalmente normal en razón de la época. Además, una buena parte de esos hombres no participaba de los beneficios de la oligarquía local. Con todo, hay datos específicos que nunca veremos en los textos árabes conservados porque, además de la propiedad de bienes inmuebles y del modo en que se repartían entre la población (dato 
omitido por las fuentes), podemos obtener otros sobre ciertos miembros de las oligarquías de la medina islámica, de aquéllos que al morir y padecer la humillación de la derrota dejaron unos bienes que el Conqueridor dio a quienes quiso favorecer.

\subsection{Oligarquías ciudadanas}

Para llevar a cabo la identificación de personas es preciso conocer su categoría o rango social. Por tanto, comencemos por saber cómo se formaba el onomástico de un varón musulmán y cuáles eran sus usos sociales en el medievo. Los elementos son: prenombre (kunya), nombre (ism), genealogía (nasab), gentilicio (nisba) y apodo, oficio o título (la$q a b)$; y se usó un onomástico abreviado (̌̌uhra).

He elegido, a manera de ejemplo, el nombre del conocido poeta, historiador y escritor valenciano Aben al-Abbār a quien la ciudad dedicó una calle en la zona marítima. De raíz familiar en Onda, nació en Valencia en 1199 y murió emigrado en Túnez en 1260 (BA, 1, n. ${ }^{\circ}$ 141). Cualquier diccionario escrito en árabe que trace su biografía dará el más completo onomástico posible, en este caso seis antecesores: Abū 'Abd Allāh (kunya) Muhammad (ism) bn 'Abd Allāh b. Abī Bakr bn 'Abd Allāh bn 'Abd al-Raḥman bn Aḥmad bn Abī Bakr (nasab), al-Qựā'ī (nisba), Ibn al-Abbār (laqab); pero cuando le citan crónicas y biografías de hombres de su tiempo usan el modo abreviado (̌̌uhra) Abū 'Abd Allāh Ibn al-Abbār.

Cita el Repartiment a Aben al-Abbār, pero no le menciona en ningún caso por alguna de las dos formas árabes (larga o abreviada) sino por su nombre (ism) y parte del apodo: "Mahomat Allabar" (B 296.10; Mahomet F 488; CF 1:1013), con casa y huerto cerca del alcázar y tierras en Campanar. Tenía otra casa cerca de un arriero de Alcàsser (al-Qașarī al-nayyār) "Algasari Anaiar" (B 199.2; F 600; CF 1:612). También dice que A(ben a)1Abbār era cuñado de "Alpatarni”" (Alpatami B 195.8; F 551; CF 1:563).

Gracias a este último dato sabemos que Abū 'Abd Allāh Muḥammad al-Bațarnī, a quien algún biógrafo moderno hace suegro del historiador valenciano, era su cuñado. Así lo indica su pariente (Ibn al-Abbār, I, n. ${ }^{\circ}$ 1018; al-Marrākuš̄i, n. ${ }^{\circ}{ }^{423}$ ), que le da la šuhra Aben al-Wazīr y (Aben) al-Bațarnī; en Valencia donde nació (573/1177), vivía en la zona que después fue partida de los hombres de Teruel, y murió en Túnez (1239). Sus casas estaban justo en el límite de la nueva judería o Call judío, cerca del baño de Abinegama (B 602.13,15,16; F 3655, Abatarn 3656; CF 3:2166, 2168, 2169).

El rey donó a Pelegrí de Bolas una heredad de "Aborrabe Abincelim salvo raallo de Arrallo" y las casas, cerca del alcázar real, de "Mahomat Allabar" (B, 296.10-297.1; F 1578; Abincelmi CF 1:1013), que al final acabaron en manos de Pedro Fernández de Açagra (B 578.17; F 3529; CF 3:1560). En la donación primera advierto otra errata de copista pues nunca hubo "raallo de Arrallo"; la anotación avisa que se debe exceptuar la propiedad de Aborrabe Abincelim ( $A b \bar{u}-r-R a b \bar{l}$ ‘ Aben Sālim) porque hacía tiempo que se había dado a Artal de Alagó "realem integrum de Aborrabe Abincelim" (B 168.6; F 222; Abincelmi CF 1:223), es decir ese "raallo de Artallo".

¿Quién fue Aborrabe Abincelim? Además de ese raal o real de Artal de Alagó, varios asientos recogen otras propiedades de este miembro de la oligarquía. Se dan casas y 5 yugadas en la heredad del "alfaqui Aborrabe" (Abonabe B 158.8; F 99; CF 1:99); otras casas de "Aborrabe Abencelim" (Aborabe B 183.11; F 392; Abinçelmi CF 1:394); o se citan bienes de "Aborrabe Abincolom" para situar otros (F 1487; Abincelmi CF 1:922). 
Bajo este onomástico se descubre a un hombre de leyes, de recta conducta, experto redactor de correspondencia oficial: Abū-r-Rabī' Sulaymān aben Mūsà, al-Kilā‘̄i, Aben Sālim, que murió mártir en la batalla de El Puig (1237). Fueron sus discípulos Aben al-Abbār y el escritor alcireño Abū-l-Muțarrif Aḥmad b. 'Abd Allāh b. Muhammad b. al-Ḥusayn b. Aḥmad, al-Mahzūmī, Aben 'Amīra (BA, 1, 445-449, n. ${ }^{\circ}$ 237), autor de una historia de la conquista cristiana de Mallorca (Ben Ma'mar, 2007). El Repartiment cita la casa de este maestro y amigo de Aben al-Abbār: "Motarif Abenhamira" (B 184.6; (Maori) F 399; mauro CF 1:401).

Otro ilustre escritor y jurista valenciano fue Abū 'Abd Allāh Muhammad b. Abrāhīm b. 'Īsà b. 'Abd al-Hamīd, al-Anșārī, Aben Rawbīl. Su padre, nacido en Onda, se trasladó a Valencia donde nació su hijo (591/1194). Fue juez de Morvedre y Valencia; luego se encargó del sermón del viernes en la mezquita aljama de Dénia; allí fue cadí y murió en 1238 (Ibn al-Abbār, 1, n. ${ }^{\circ}$ 1008; al-Marrākuš̄i, 6, n. ${ }^{\circ}$ 251). El nombre Muhammad Aben Rawbīl ha sufrido cambios en los asientos: en el barrio de "in vico de Alabedin" (al- 'ābidīn los esclavos) poseía casas "Mahomat Abinraubil" (B 202.11; Abintaubil F 646; Abincaubil CF 1:658); en un huerto de "Mahomat Abinraubel" se dan 8 hanegadas menos un cuarto (F 461; Aben Rault CF 1:464); repetida cesión de "orto de": "Mahomat Abincaubil", "orto predicti Mafomat Abincaubil”, "Abincaubil” (B 189.2,3,4; Abintaubili, \Mafometi/ Abintaubili, Abintaubil F 471; CF 1:474, 475, Mahomat Abincaubili 476); más un “orto de Abinraubil (?)" (F 1180, Abintaubil (?) 1181; Abnumabib CF 1:1415, 1416).

Aún añadiré a Abū-l-Ḥasan Muḥammad, hijo del alfaquí Abū 'Abd Allāh Muhammad (1133-1211), maestro de Aben al-Abbār, juez en varias localidades del oriente andalusí y a su vez hijo del que fuera cadí de Alzira Abū Muhammad Ayyūb (m. 576/1180) (BA, 4, 340-342, n. ${ }^{\circ}$ 921). En el siglo VIII sus antepasados gāaiqíes se instalaron en Zaragoza y dos siglos más tarde un descendiente muy longevo recibió el apodo de "el Noé" (Aben $N \bar{u} h$ ) que adoptó la familia desde entonces.

Jaime I hizo donación a Nunyo Sanç de las casas y heredades de "Albehaçan Abunho et de Albehaçen Abunho et balneum de Amrem Nuno" (B 187.11; Amem F 455; Anrem CF 1:458); esto es, Abū-1-Hasan Muhammad Aben Nūḥ y su pariente 'Amr Aben Nūḥ; en otros asientos sirve de orientación la casa de "Alboaçan Abenho" (B 196.2; F 557; CF 1:569) o el "balneo Nunonis" (B 286.8; F 1471; CF 1:1705).

El Repartiment recoge en dos ocasiones los bienes de su hermano Abū Bakar 'Abbās. Registra la casa con establo dada al maestre Joan Trinitaris (Habenbequer Abenho F 1532; Habobequer Abenhe CF 1:967) y otra al maestre Joan Nuño de este "Abubecher Abenho" (B 293.6; F 1546; CF 1:981). El nombre familiar se repite en otra donación hecha a Don Nuno Sanç, esta vez tachado por error del escriba (ububecha Habenho F 1576; [Ubecher Habenho] CF 1:1011).

He elegido solo una pequeña muestra de la élite valenciana que cita el Repartiment entre los muchos individuos cuyos onomásticos completos conocemos por las fuentes árabes; puede servir para ilustrar la dificultad de identificar -sin errores- los personajes árabes que recoje el registro cristiano editado del reparto de la ciudad y reino de Valencia.

\subsection{Las mujeres}

¿Qué sabemos de las mujeres? Las fuentes árabes apenas las citan y el Repartiment recoje unas pocas, en su mayor parte sin incluir el onomástico, casi todas hijas y esposas de 
familias cuyos nombres remiten a hombres del gobierno, de la administración del Estado o de la oligarquía ciudadana. Es el caso de una mujer de los antes citados Aben Nūḥ, llamada Umm al-Faraj y hermana de (A)Bū(ba)krūn: "Homalfaraix, sorore Bocron Abunho" (B 251.9; F 1198; Bocren Abumho CF 1:1434). También está una hija de "Abolhamalet" (Abū-l-Hamlāt) de nombre "Saxona" (B 198.10), "Gayona” (F 594) o "Gaxona" (CF 1:606). Pienso que es Ġayyūna. Podría ser hija del "raiç Abolphamalet” que negoció con Jaime I la rendición de la ciudad de Valencia. El rey le nombra en su Llibre del feyts (cap. 272, 274, 277, 279) donde transcribe el discurso que le trasladó en nombre de Zayyān b. Mardanīš y las quejas del gobernante por el asedio de la ciudad. Este Abū-1-Hamlāt del Llibre fue un primo hermano de Zayyān. Sin que se pueda rechazar esa posibilidad, la persona citada en el Repartiment pudo ser un hermano, pero como Mudāfi', padre de Zayyān, llevó la kunya Abū-1Hamlāt, es posible que "Gayona” fuera hermana del $r a ' \bar{l} s$ de Valencia.

Nueve óptimas casas en los alrededores del alcázar, que fueron de "Abohamalet”, obtuvo Pedro Fernández de Azagra que en el mismo lugar poseía las del escritor Aben alAbbār (Abohamalit B 578.17; F 3529; CF 3:1560).

Es significativo que los escribas cristianos mantengan alguna vez, sobre todo respecto a las mujeres, las voces árabes que reflejan su parentesco con hombres. Por ejemplo, se citan tres hijas de familias destacadas en el seno de secretarios, cadíes y alfaquíes de la oligarquía local en la donación de unas casas. Una (Abent) pertenecía a los 'Ayyāš y las otras dos a los Bībaš, apodos muy usados en al-Andalus y cuya identidad no es posible aislar; filiación que está unida al nombre familiar "Abentabibeix et de Abentaxat et de Ebentabibeix" (Abentaxac B 207.6; F 1584; CF 1:1019), cambiado en "Abentaçrat et Abitabilel" en el parcelario de la medina (B 520.1; F 3224; Abentaxat CF 3:116). El Repartiment llama "Haytona" (Haytūna) a una hija de Abenvinaix (B 292.8; [Abinvaix] F 1531; CF 1:966) ${ }^{6}$. Advierten las ediciones que el copista tachó el primer Abinvinaix, que añadió después de hija, de forma correcta.

En otro lugar del libro el escribano tachó la voz árabe que había transcrito y añadió la traducción: "Hayça nepote Amberrecan" (B 211.1; Hacyça (Afidet) F 750; Haeyça (Afidet) CF 1:761) (que en árabe sería 'Azīza o 'Izza, hafídat Aben Barrajān) o sea la nieta de Ibn Barrajān, un famoso ulema sevillano de pensamiento sufí (BA, 2, n. $\left.{ }^{\circ} 387\right)$. La mujer vuelve a salir después, "Eyça Amberraga", con omisión de parentesco (B 298.9; F 1596; CF 1:1031).

En otro lugar el escribano no traduce "Zaugi Hubecar Almatro", cuya casa se libró "pro stabulo" (B 249.7; F 1174; CF 1:1409). Era la esposa (zawj) de (A)bū Bakar Aben Matrūḥ a quien en otro lugar se dice "Alfaqui Mahomat Almatro" (Almacro B 201.9; F 633; CF 1:645) y en otro "Hubecar" (Almacto B 158.1; Almatia F 90; Almato CF 1:90). Hay razones para creer que estaba casada con un miembro de la familia de 'Abd Allāh b. Muḥammad, at-Tujīī̄ī, Aben Mațrūḥ, juez de la capital y de Dénia, maestro de Aben alAbbār que murió durante el asedio de Valencia (Ibn al-Abbār, 2, n. ${ }^{\circ} 1053$ ).

Hay ejemplos de mujeres vinculadas a musulmanes cuya profesión podría incluirse entre las “artesanales". Por ejemplo, la hija de un hombre de Llíria, llamado Yūsaf, de profesión hajjām o alfajeme, esto es barbero, sangrador que en la época también extraía muelas. Es curioso que su casa se diera a Felip "barbitonsor". En las ediciones del Repartiment su ono-

\footnotetext{
"Se cita además a un hijo: "Brahim Huarat Benvives" (Abrāhīm warat Aben Bībaš) que tenía un campo en la Russafa (B 234.3; Binvives F 1049; CF 1:1278) y casas en la ciudad (CF 1:980, 983).
} 
mástico varía: "Jussef Aleti Alagem" (B 172.4); "Jucef Aleri Alhagen” (F 257); "Iucef Aleti Alhagem" (CF 1:258); el nombre de su hija, "Annutelleri Alhagem” (Annucelleri B 288.5; F 1486; CF 1:921), en el manuscrito árabe imaginario pudo haber sido Avnit el_Leri, al_hagem (Abnat al-Lirī, al-hajjām), esto es, la hija del de Llíria, el barbero.

\subsection{Grupos de poder}

Los grupos de poder, sobre todo los miembros de la familia gobernante, visires y personajes de la Corte, alcaides, notarios, literatos y escribanos han recibido mucha más atención que otros musulmanes de la sociedad urbana valenciana. Varios estudios se han ocupado de Abū Zayd, último gobernador almohade, que por ponerse de lado de Jaime I y por su conversión cristiana ha despertado interés, desde el siglo XVII con el cronista Escolano a la cabeza.

El mismo efecto de simpatía suscitó al final del siglo XIX Aben Mardan̄̄š, antepasado del gobernante Zayyān. Parte del interés en el "rey Lobo o Lope" -llamado así por el papa de Roma- radica no tanto en su convivencia con los soldados cristianos que tenía a sueldo sino sobre todo en su independencia frente a los almohades en la segunda mitad del siglo XII. Las crónicas árabes le llaman el príncipe del Este de al-Andalus (amīr al-šarq). Las crónicas alaban la pugna anti-almohade de Muḥammad b. Sa dd, al-Jud̄āmī, Aben Mardanīš (m. Murcia 1172) desde sus dominios que iban de Tortosa a Granada.

Tras su muerte, la familia aceptó el credo almohade y fue ratificado gobernador de Valencia el $r a$ '̄̌s Abū-l-Hajjāj Yūsuf b. Sa'd (m. 1186), abuelo de Zayyān y hermano del "rey Lope". Es difícil seguir la trayectoria de una familia tan poderosa porque no se han resuelto todos sus lazos ni se ha hecho la necesaria crítica de los datos que dan cronistas árabes tardíos como Ibn Haldūn e Ibn al-Hुațīb. Hace tiempo que los investigadores buscan en el Repartiment la huella familiar, pero de manera superficial, cometiendo -a mi entender- algún error de identificación grave o dejando de lado datos relevantes.

Pondré un ejemplo. Entre las donaciones iniciales del primer libro hay una que concede a Ramon de Ribes casas de "raheç Amahomat et ortum suum cum duobus campis suis" (B 181.8; F 372; CF 1:374). Al poco el rey hizo donación a Pere Cornell, mayordomo de Aragón, de las casas de "rayç Abdalla Çab Albaçair" (Raiz B 240.2; F 1096; rayç CF 1:1332) o simplemente "Rayz Amahomat" (B 583.22; F 3553; CF 3:1673).

También se dio a Bernat de Terol un molino de cinco muelas de este "Raiç Amahomet Zayp Albacet", situado entre las puertas de "Exarea et de Açahar" (B 322.1; Zayb F 1778; rayç Amahomet Zayp CF 1:1792); más adelante se repite "Rayz Amahomat Çayp" (B 377.4; F 2260; Cayp CF 2:105). Este es el molino "de les cinch moles" que aun existía en el siglo XIV junto al convento de Sant Francesc, donde está Capitanía General (Barceló, 2000a, 44). Además, en el Llibre hay una cesión de otro molino de solo una rueda de "rayç Amahomat" (rayz F 1790, 2271; CF 1:1805, 2:116).

Sin duda el amo musulmán de todos aquellos bienes es el bisabuelo de Zayyān, Abū Muhammad 'Abd Allāh b. Muhammad b. Sa'd aben Mardanīš. Desposó a la hija del cadí Aben 'Iyāọ, un hombre de leyes que en 1145, durante la etapa de las segundas taifas, se alzó con el poder independizándose de los almorávides en el Este peninsular. Dos sobrinos suyos, Muḥammad y Yūsuf b. Muḥammad b. Sa'd aben Mardanī̌s, fueron gobernadores en Valencia y en Murcia y su hijo 'Abd Allāh fue gobernador de Almería en nombre del 
“rey Lobo o Lope". Este ra'̄̄s Abū Muhammad llevó el apodo en los cronistas árabes de "el (mártir) de Albacete" (șâhib al-Basīt ț) porque murió cerca de Chinchilla en la batalla contra Alfonso VII de Castilla en 1146, junto a Aben Hūd al-Mustanșir Sayf ad-dawla (Codera, 1899, 86-87), "Zafadola" en la versión cristiana del título de honor "Espada del Estado" que los califas otorgaban al hạjib.

Cabe preguntarse cómo los bienes de Abū Muhammad șāhib al-Basīt, muerto hacía más de medio siglo, mantienen su nombre. Es posible que los inmovilizara, haciendo de ellos donación inalienable (bien de manos muertas), llamada habis o habus, esto es habices, entre los juristas del Islam occidental. Aunque fue mal vista por la ortodoxia cuando beneficiaba al heredero, era recurso habitual para mantener lejos de expropiaciones, codicia o capricho de los gobernantes la hacienda familiar. Otra posible respuesta sería que para distinguirse de otros Aben Mardanīš su descendiencia adoptó el apodo. Pero de ninguna de ambas hipótesis existe constancia.

Citaré otro caso más. Jaime I otorga a su escribano Guillem "reallum et ortum de Galip Ibunmardunix" (B 157.1; Abanmardanix F 76; Aben Mardanix CF 1:76). Sin duda es Abū-1-Zafr Ġālib, primo hermano de Zayyān, que citan las crónicas árabes. Unos asientos después el huerto resulta ser de "filia de Galip, uxore de Nemi Ibanmardanixi iuxta ortum de Mahomat Sefir Mardaxini (?) et est inter portam de Bebalcantara et de Bebalurrach" (B Galis, Nemis Abanmardanixi, Bebalcautam, Bebalvirach 157.8; F 87; filia de Gali Iban Mardanixin, uxore de Nemis, iuxta ortum de Mahomat. Et est inter portam de Bebalcantera et de Bebalrrach CF 1:87).

De nuevo estamos ante fincas de miembros de la familia de Zayyān. La hija de su primo Ġālib estaba casada con otro Aben Mardanīš, cuyo nombre árabe es difícil de interpretar en la versión gráfica latina. El asiento dice que el huerto estaba junto al de Abū 'Abd Allāh Muḥammad, pariente del "rey Lope" pues era "sefir" (sihr) -yerno, suegro o cuñado- de Aben Mardanīš. El huerto de "Galip Bardanix" entre las puertas del Puente (alQanțara) y del Librero (al-Warrāq) estaba junto a otro situado junto al río, donado a un sedero musulmán residente al lado de "Habemnuno" (Aben Nūhn) (B Galsp 184.2; \Hahem Nuno/ F 394; Hahemnuno CF 1:396).

Se conocen mejor las citas que da el Llibre de los bienes del padre de Zayyān. El obispo de Barcelona recibió un real "rehallum" o "reallem" (riyād) que estaba en Beniferre (B 245.5; F 1145; CF 1:1380) de "Modef patre de Çayen" (B 174.8; F 295; CF 1:297). Pedro Fernández de Açagra se benefició de las casas que tenía en la plaza del Juez o Al-

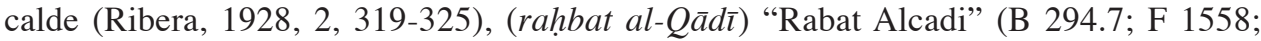
CF 1:993). También aquí hay otro habus, ya que Abū-l-Hamlāt Mudāfi', hijo del gobernador Abū-1-Hajjāj Yūsuf y padre de Zayyān, murió joven, tal vez durante la campaña de los almohades contra Santarem en 1184 mientras su primo Abū 'Abd Allāh b. Abī Sulțān 'Azīz ocupaba el cargo de gobernador en Alzira (Huici, 1970, 3:197). Las abundantes citas en el Repartiment del "rayç Abiçolta" requieren un estudio independiente.

En cuanto al gobernador almohade sayyid Abū Zayd, recibió las heredades que su padre tuvo en Cullera y Corbera más la casa en Valencia de su madre. A cambio del real que se quedó el rey Jaime I, obtuvo la "muniam de Exarea et fuit de Abensalbo" y un real de “Abdela Abensalbo" (B 195.7; F 550; CF 1:562). Quizá el dueño de munya y riyād fuera el gramático valenciano Abū 'Abd Allāh Muḥammad b. Yahyà b. Xalaf b. Yaḥyà b. Xalaf, al-Anșārī, Aben Šalbūn (m. 599/1202) (Ibn al-Abbar, 1, 282, n. ${ }^{\circ}$ 872). 
Me pregunto si es el mismo Aben Šalbūn del que pasaron a Gil Garcés siete casas de "Abensalbon" (B 606.21; F 3676; CF 3:2274) o “Abisalbon" (B 607.4; F 3678; CF 3: 2279) y casas, huertos, "rahallos", hornos, molinos y cualquier otra heredad que hubiera tenido "Abinsalbo" en la ciudad y en todo el reino (Abinsalvo B 234.1; F 1047; CF 1:1276). Por otra parte, a Ramon Saniez se dieron casas de "Mahomat Abenxalbon" y otra de "Abin Salbon" (Abenxalbo B 554.12; Abinsalbon F 3402; CF 3:1302).

En ningún caso este Mahomat puede identificarse con el poeta de segunda fila Abū-1Hasan 'Alī b. Lubb b. 'Alī, al-Ma'āfirī, Aben Šalabūn, que salió de Valencia (1228), donde había sido secretario de la administración de Abū Zayd y de su padre; en Murcia trabajó para el califa al-Mutawakkil Aben Hūd y en Marrakech, donde murió (1241) fue bibliotecario (al-Marrākušī 5.1, n. ${ }^{\circ}$ 550). Su casa se dio a Guillem de Veruela pues según el asiento era de "Ali Abenxalbon Açaban" (Abexalbon B 546.20; F 3362; Abenxalbo CF 3:758), es decir 'Al̄̄ aben Šalabūn.

La confrontación de la lista de personajes biografiados o citados en las fuentes árabes con los nombres del Repartiment nos procura identificaciones seguras y una interesante lista de individuos aún por concluir, pues hay posibilidad de ampliar su número.

\section{TOPOGRAFÍA DE LA CIUDAD}

El análisis de los datos del registro real nos introduce en otro aspecto: la topografía de la ciudad, con la localización de recursos hídricos, mercados, actividades artesanales y comerciales, además de las explotaciones agrarias, pequeñas y grandes. Añadiré, aunque es un tema que no trataré aquí, que los datos sobre las propiedades o fincas con algun sistema de riego directo permiten contabilizar de manera aproximada no menos de cinco almunias (munya), unos 150 huertos (janna) y un centenar de reales (riyād).

Hago un inciso para aclarar que raal no es siempre el árabe rahal (masía, casa de labor) como argumenta con insistencia un determinado sector de historiadores de al-Andalus. Ya dijo Escolano (libro VIII, capítulo 26, columna 930) que Raal en árabe era "casería puesta en la ribera de algún río"; señala un tipo de población en la huerta, como vemos en el sinónimo "ort sive real" del Repartiment y otros textos latinos. Hay casos de "rahal" que son molinos, en árabe rahà (Barceló, 1985, 33). La forma dialectal riyād (huerto, jardín) es el étimo de Riad (capital saudita), dos El Real (paseo al otro lado del Turia en Valencia y El Real de Gandía) y una mansión en Málaga hecha por el califa al-Ma'mūn (1226) (riyād al-sayyid), llamada jannat al-sayyid y en la etapa nazarí qașr al-sayyid (Calero, Martínez, 1995, 395-398).

Intervenciones arqueológicas de urgencia en solares de la ciudad han ratificado buena parte de los datos del Repartiment. Ello permite avanzar en la comprensión de la antigua medina. Por eso solo me referiré a la puerta "de Boatella" como llaman los cristianos a la que los árabes denominaron bāb Buyțāla. Se abría en dirección sur, la defendía una barbacana y a corta distancia la protegía una torre avanzada, exterior a la muralla y acaso comunicada mediante muro. Por esa razón al iniciar el asedio Jaime I ordenó prenderle fuego (Barceló, 1977, 178). El Repartiment llama a ésta "turrim cremata"; tenía cerca tres casitas de un musulmán colaborador (B 306.4, 249.2; F 1126, 1670; CF 1:1105, 1404).

Podemos sospechar que se trataba de una torre albarrana que protegía la puerta y la barbacana, como aquella en la que vio Don Jaime a Zayyān; torre similar a las que se ven 
en murallas islámicas de Jaén, Talavera de la Reina, Toledo o Córdoba. Describe el Repartiment "furnum inter abbas (sic) portas de Boatella", es decir con acceso en doble recodo, con una forja en su interior (B 325.1; F 1797; CF 1:1812). La puerta daba paso a una zona dentro de la ciudad que presidía una portada de cinco arcos que comunicaba con una calle interior -que podría coincidir con la actual de Sant Vicent- en la que, además de talleres y tiendas a uno y otro lado, había varias alhóndigas o fondas. Era la salida de la ciudad al sur: Russafa y las ciudades de Alzira, Xàtiva, Dénia, Murcia, Córdoba, antigua capital del califato andalusí, y Sevilla, sede del gobierno almohade.

\subsection{Barrios}

Intramuros la estructura de la ciudad giraba en torno a entidades pequeñas, con una o más calles, llamadas en árabe $a z-z u q \bar{a} q$. Esta era la voz andalusí para "calle"; adoptada por el catalán como "atzucac", significa "callejón sin salida"; se debería evitar su uso en relación con el Repartiment. Contabilizando las donaciones, aquellas vías, algunas veces llamadas vico o calle, tenían entre 15 y 25 casas, capacidad que pudieron tener otros barrios interiores (Barceló, 2000a, 47).

Algunas llevaban el nombre de alguien notorio, como el "cuchach de Abinjahaf" (Dabin Jahaf B 307.10; F 1687; Abiniahaf CF 1:1122), por la familia del cadí Aben Jahhāf (Ribera, 1928, 2, 214-219; Huici, 1970); o "çuchach Abenadir" (B 242.10; F 1123; CF 1:1359), nombre familiar del cadí, alfaquí y notario Abū 'Āmir Nadīir b. Wahb b. Lubb, al-Fihrī, Aben Nadīir (Ibn al-Abbar, 2, 424-425, n. ${ }^{\circ}$ 1217), juez de Denia en 636/1239. El Repartiment cita su casa ("alfaqui Abenadir" [B 207; F 1581; CF 1:1016]) y la de sus parientes "Alī ("Ali" B 267.1; F 1308; CF 1:1541; “Aly” B 282.3; F 1435; CF 1:1667) y Muhammad aben Nadīir ("Mahomat" B 194.5; F 535; CF 1:547).

Recordemos los Aben 'Atțūš, entre los que destacó en el siglo XII un famoso calígrafo (Ribera, 1928, 2, 304-308). Llevaron su nombre: "carraria de (çucach) Abinatos" (B 162.5; F 159; CF 1:159), "Ivicco de Abenaatoix/" (F 710; Abenaacoix B 207.12, CF 1:722), "barrio de Hatoix" (B 224.4; F 927; CF 1:1156), "calle de Binhacoix" (B 210.1; CF 1:747; Binharoix F 736) y "Rahabatatox", plaza en la que empezaba la partida de Zaragoza (B 544.16; F 3352; Rahabatacox CF 3:709).

Otros barrios se nombraron por una mezquita o "misquitam", como la de "Açaquen", que daba nombre a un "acuchac" (zuqāq al-saqqā'̄n de los aguadores), alrededor de la actual iglesia de San Juan del Hospital (B 205.9, Daçaquena 301.9; F 682, 1626; CF 1:693, 1061). Cerca de algunas había pozos y aljibes públicos, que tomaron el nombre de la persona o familia que como legado piadoso encargó su construcción. Localizado donde después se alzó la parroquia de Sant Bartomeu, el Repartiment cita dos veces el que dio nombre a un barrio. Se llamó “vico de Bir Boamel”, es decir el pozo de Abū 'Amīọ (Bir... B 299.7; F 1604; Bir Utiel CF 1:1039) o "calle de Virboamel” (B 184.5; F 398; CF 1:400); hay que situarlo en la partida de los hombres de Teruel. Sería un aljibe formado por depósitos cubiertos con bóveda en U.

Los musulmanes construyeron en el barrio de la plaza del Juez Raḩbat al-qā $d \bar{\imath}$, donde vivía la élite de Valencia, una balsa para su servicio que quizás se encontrara cerca de la actual iglesia de Santa Catalina. El Repartiment alude a ella al citar birkat Aben Hamīs, "bassiam" que coloca "in via Davenhamiç" (B 306.6; (calle) \via/ F 1672; CF 1:1107), o 
"in vico de Becar Abenhamiz" (B 222.6; Bercat F 905; CF 1:916) o de "Becat Avinhamiz" (B 294.1; F 1552; CF 1:987), tal vez el nombre de la piadosa persona que estableció el habus. Entre estas donaciones pías un número considerable de casas se daban en propiedad a una mezquita para su mantenimiento.

Una semana después de la entrada cristiana se concede la carnicería. Se instala en el lugar de la islámica, como señala el documento latino de donación "in quo carniceria erat iam tempore sarracenorum". Sus lindes son las calles de drogueros (alatares al- 'atțārīn), alfareros (altahari al-fahḩ̄̄rīn), buñoleros (açafegi as-saffājīn), bordadores de țirāz (tarahisi țarā’izīn) y el almudín del trigo (Huici, Cabanes, 1976, 52, n. ${ }^{\circ} 287$ ) y se le cede un corral para matadero, llamado almudino. Siguiendo los usos cristianos, el rey ordenó instalar la pescadería junto a la carnicería (Huici, Cabanes, 1976, 53, n. ${ }^{\circ} 288$ ).

Es muy probable que la Alcaicería, lugar cerrado para la venta de productos de lujo (por ejemplo tejidos de seda), se encontrara a occidente de la mezquita aljama principal (Barceló, 2000a, 45), próxima al sitio en el que más tarde se donaron unas casas para hacer la púrpura "iuxta Sancta Maria ut in eis faciant purpuras" (B 285.10; F 1463; CF 1:1697). Cita el Repartiment unas 30 fondas para viajeros y mercaderes y a 5 sederos (alcassez, alqazzāz).

Las tiendas de la ciudad eran edificios de dos pisos. El Llibre usa la voz árabe al-gurfa "algurphiis", referida al sobrado de dos tiendas junto a una fonda (B 316.1; F 1741; CF 1:1756); indicación que reitera en más de diez ocasiones. En la planta baja estaba el taller o almacén y delante se ponía la mesa (árabe $d u k k a ̄ n$ ) para exponer los productos.

\subsection{Los artesanos}

La onomástica de los ocupantes de algunas calles podría revelar su oficio. Aunque debemos ser cautelosos con estas identificaciones pues en al-Andalus el apodo de muchos estudiosos y literatos es un nombre de oficio (Ibn al-Abbār, Ibn al-Labbāna, etc.), hubo determinados artesanos de la ciudad islámica viviendo en áreas especializadas en el trabajo en madera, metal, piedra, alimentos y ciertos productos (drogas, medicamentos, especias, telas, tejidos), además de la venta de granos y animales; todos se consideran hoy sectores del equipamiento urbano. Con todo, pueden citarse oficios, identificados en la grafia latina del Repartiment, agrupados por sectores:

a) en la construcción, además de albañil (albanne al-bannā'), carpintero (anagar, anaxar an-najjār), adobero (atauab ad-dawwāb), cedacero (algarbal al-garbal), tornero (alharrat $a l$-harrāt) y tallista (anacax an-naqqās), hay grupos de pintores (atdahenin ad-dahhā$n \bar{\imath} n$ ), cesteros (çaleli as-sallālīn) y fabricante de serones (alcafiphi al-qaffāfīn);

b) en la indumentaria, junto a peletero (alfarra $a l$-farra's'), curtidor y pellejero (adabag

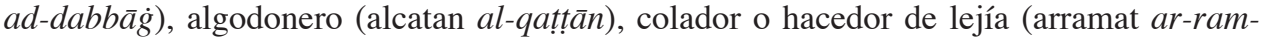
$m \bar{a} d$ ) y fabricante de tapines y alcorques (alcarrac al-qarrāq) o escudos y defensas (atarraç at-tarrās), hay grupos de fabricante de peine o rastrillo (almaxeti al-mašățīn) y de curtidores (galladi al-jallādīn);

c) en la alimentación, aunque algunos cocineros iban itinerantes por las calles de la ciudad islámica, el Llibre cita al que hacía harisa (alharraz al-harrās) y al buñolero (açafeg as-saffajj); otros oficios de este ramo son: carbonero (alfaham al-fahhām), harinero (alhanat al-ḥannāt), olleros (alfahari al-fahhāāinn) y vendedores de sal (anumalahin, al-ma- 
llaḥ̄n); aquí se cuentan los hornos de cocción del pan repartidos por la ciudad, como uno de "Almageem" (al-mahzan el estado) donde estaban los carniceros, con lindes en "via de Tarayfin" (țarā'iḥinn), baño y fonda (B 324.3; Almagcem F 1794; CF 1:1809);

d) seguramente del mismo tipo "furnum" eran los hornos de fundición del metal como descubre la donación de uno "in vico Ferrarie" (B 325.5; F 1802; CF 1:1817). El Repartiment recoge otro "in barrio de Laxacof" (ǎ̌-šāqūf el martinete) (Laxacef B 324.6, 382.2; F la Xocaf 1540, 1796; CF 1:975, 1811). Donde estaba la carnicería se hallaba un "furnum" de fabricantes de puntas de flecha o lanza; árabe al-qūša min aț-țarā'ifín amāma zuqāq Aben Haldūn que varía con grafía latina en las ediciones: "furnum illum cum domibus de Alchuxa de Atarahifiri ante viam de Habenbaldo" (B 324.3, Atarahifin F 1792, CF 1:1807) y "Alxuxa Ataraifi ante viam de Abinfaldon" (B 382.1; F 2290; CF 2:135).

La vinculación de la capital con la actividad marítima se refleja en el Llibre en la donación a B. de Calvera de un inmueble aislado, "cum omni hedificio que nominatur Benibahary" (B 245.7; F 1147; CF 1:1382), que dio nombre al lugar de "Benibahari" donde se dieron tierras al mismo Calvera (B 275.4; F 1379; CF 1:1612). Tal vez sea el árabe binā'l-bahhậrīn esto es "la casa de los hombres del mar" o "los marineros".

\section{A MODO DE CONCLUSIÓN}

En conjunto, el Repartiment oculta bajo letras latinas una serie de datos que, debidamente trabajados y cotejados con los de otras fuentes, permitirían ampliar la visión que ahora se tiene de la ciudad islámica. El principal peligro de esta tarea es olvidarse de que trabajamos sobre un manuscrito cuya huella árabe está oculta por efecto de ediciones poco exigentes. Por eso se debe efectuar una nueva lectura, cuya conveniencia reivindico aquí, para entender la sociedad musulmana de Valencia en la primera mitad del siglo XIII.

\section{BIBLIOGRAFIA}

IBN AL-ABBĀR. Takmila li-kitāb al-Șila (1888-1889): Codera, F. (ed.), Madrid, Mestre (Bibliotheca Arabico-Hispana V y VI), 2 vols.

AL-MARRĀKUŠİ. al-Ḍayl wa-l-takmila li-kitābay al-Mawṣūl wa-l-Ṣila (1965, 1973): 'Abbās, I. (Ed.), Beirut, Dār al-țaqāfa, vols. V, 2 tomos-VI.

BA = Lirola, J. (Dir.) (2003-2009): Biblioteca de Al-Andalus, Almería, Fundación Ibn Țufayl, 9 vols.

BARCELÓ, C. (1977): “Algunas notas sobre la ciudad islámica de Valencia”, en: Homenaje a don José María Lacarra de Miguel en su jubilación del profesorado, Zaragoza, Anubar, 2, 175-186.

BARCELÓ, C. (1983): Toponímia aràbiga del País Valencià, València, Institut de Filologia Valenciana (Biblioteca Sanchis Guarner 8), 312 p.

BARCELÓ, C. (1984): Minorías Islámicas en el País Valenciano. Historia y Dialecto, Universitat de València, Madrid, Instituto Hispano-Árabe de Cultura, 399 p.

BARCELÓ, C. (1985): “Toponymie tribale ou familiale et organisation de l'espace dans l'aire valencienne à l'époque musulmane", Revue de l'Occident Musulman et de la Mediterranée, 40, 29-38.

BARCELÓ, C. (2000): “Topònims valencians en patronímics àrabs del 'Llibre del Repartiment' de València", en: Mateu, J. F., Casanova, E. (Ed.), Estudis de Toponímia Valenciana en honor de Vicenç M. Roselló y Verger, Valencia, Denes, 61-77. 
BARCELÓ, C. (2000b): "Valencia islámica: espacio y paisaje urbano", en Dauksis, S. y Taberner, F. (Eds.), Historia de la ciudad. Recorrido histórico por la arquitectura y el urbanismo de la ciudad de Valencia, Valencia, Colegio Territorial de Arquitectos de Valencia, 40-50.

BARCELÓ, C. (2010): Noms aràbics de lloc, València, Bromera (Essencial 13), 162 p.

BEN MA`MAR, M. (Ed.) (2007): IBN 'AMĪRA. Ta'rīj Mayūrqa, Beirut, Dār al-kutub al-'ilmiyya, $160 \mathrm{p}$.

BOFARULL, P. de (Ed.) (1856): "Repartimiento de Valencia", en Repartimientos de los reinos de Mallorca, Valencia y Cerdeña, Barcelona, Archivo de la Corona de Aragón (CODOIN XI), 151656.

CABANES PECOURT, M. ${ }^{a}$ D., FERRER NAVARRO, R. (1979-1980): Llibre del Repartiment del regne de Valencia, Zaragoza, Anubar, 3 vols.

CALERO, M. ${ }^{a}$ I., MARTíNEZ, V. (1995): Málaga, ciudad de Al-Andalus, Málaga, Ágora, 536 p.

CHABÁS, Roque (1888-1893): "El libro del Repartimiento de la ciudad y reino de Valencia", El Archivo, III (1888-1889), 73-98, 118, 217-225; VI (1892), 240-250; VII (1893), 365-372.

CODERA, F. (1899): Decadencia y desaparición de los almorávides en España, Zaragoza, Comas, $421 \mathrm{p}$.

CORRIENTE, F. (1992): Árabe andalusí y lenguas romances, Madrid, Mapfre, 270 p.

ESCOLANO, G. (1610): Década primera de la Historia de la Insigne y Coronada Ciudad y reyno de Valencia, Valencia, Patricio Mey (facsímil Universitat de València, 1972), 6 vols.

FERRANDO, A. (Ed.) (1979): Llibre del Repartiment de València, València, Vicent García Editores, 2 vols.

HUICI, A. (1970): Historia musulmana de Valencia y su región. Novedades y rectificaciones, Ayuntamiento de Valencia, Anubar, 3 vols.

HUICI, A. (†), CABANES, M. ${ }^{a}$ D. (1976): Documentos de Jaime I de Aragón. II. 1237-1250, Valencia, Anubar, $370 \mathrm{p}$.

LABARTA, A. (1989): La onomástica de los moriscos valencianos, Madrid, Consejo Superior de Investigaciones Científicas, $255 \mathrm{p}$.

Llibre del feyts $=$ Llibre dels fets del rei En Jaume o Crònica de Jaume I, F. Soldevila (1971): Les quatre grans cròniques, Barcelona, Selecta (Biblioteca Perenne 26), 1300 p.

McKITTERICK, R. (2007): "Palimpsests: Concluding Remarks", en: Declercq, G. (Ed.), Early Medieval Palimpsests. Procedings of the workshop Early Medieval Palimpsests (Brepols, $8 \mathrm{Fe}$ bruary, 2002), Turnhout, Brepols (Bibliologia 26), 145-151.

RIBERA, J. (1928): Disertaciones y opúsculos, Madrid, Mestre, 2 vols. (La historia de Valencia, publicada en Almanaque de Las Provincias y El Archivo, en 2, 177-336).

RIBERA, J. (1939): Repartiment de Valencia. Edición fotocópica con un prólogo de..., Valencia, Centro de Cultura Valenciana [reprint (1952): Opúsculos Dispersos, Tetuán, Instituto General Franco de Estudios e Investigación Hispano-Árabe, 39-67]. 